of the Edinburgh Geological Society on March 9. The map, which belongs to the Geological Society of London, is based in part on information supplied to Necker by other geologists and in part on his own extensive travels in Scotland. Tho map has never been published, and in view of its historical importance, it is hoped to roproduce a colour facsimile. Mr. Eyles said that Necker, who was born in Switzerland, went to Edinburgh in 1806, and studied geology under Prof. Jameson at the University. He was a grandson of de Saussure, the famous Alpinist and geologist; he was related to Madame de Stael, the novelist, and to Necker, the financier, a minister of Louis XVI. After leaving Edinburgh in 1808, he became professor of mineralogy at Geneva, and travelled extensively in Europe. In 1821, he published an account of his travols in Scotland in a three-volume work entitled "Voyage en Ecosse et aux Iles hébrides". He returned to Edinburgh on sovoral occasions. In 1841 he retired to Skye for reasons of health, and remained there until his death in 1861 . $\mathrm{He}$ was buried at lortree.

\section{Comfort in Travel}

At the annual joint meeting of engineering and technical societies organized by the Institution of Automobile Engineers and held on March 10 at the Institution of Civil Engineers, three short papers wore read on "Comfort in Travel". The first paper was on road travel by $\mathrm{S}$. Garcke, the second on rail travel by Lord Stamp, and the third on air travol by Capt. E. W. Percival. Mr. Garcke pointed out that much of the improvement in the comfort in travel by road is due to the improvements of the surface of the roads. The invention of the railway was essentially the product of necessity, and was mainly due to finding something better than the wator-bound flint or stone road. It seems improbable that further marked improvements in road surfaces can be anticipated. The discomfort due to nervous reaction imposed upon a driver by the presence on the road not only of many signals, but also of advertisements, lights and other contrivances, readily confused with official signs, is very real. Such signs are now greatly on the increase and will have to be controlled.

LORD STAMP laid stress on two clements in rail travel : mental ease and physical ease. Mental ease is promoted by removing difficulties in the way of finding out how to go and when to go. Throughout the United States and Canada many agencies have been established by the British railways, all with the object of easing matters for the customers. Physical easc is promoted by absence of disturbing vibration and noise and by the provision of adequate heating, ventilation and lighting. The L.M.S. Co. has employed eminent men of science in Great Britain to solve some of their problems, and both here and in the United States the motion of tyres of different profiles have been studied by means of cinematograph records. It has been found that a profile as nearly cylindrical as possible gives the greatest freedom from high-frequency lateral oscillations.
Captain Percival considers that the devolopment of the aeroplane has progressed more rapidly than that of any other form of transport vehicle. For very large cities it will soon be essential to have several main aerodromes so as to take care of the everincreasing traffic.

\section{Social Survey of Bristol}

A PRELIMINARy report on tho standard of living in Bristol, by H. Tout, has been issued by the University of Bristol Social Survey, of which Mr. Tout is director ("The Standard of Living in Bristol: a Preliminary Report of the Work of the University of Bristol Social Survey." By Herbert Tout. Pp. 64. Bristol and London: J. W. Arrowsmith, Ltd., 1938. $1 s$. net). The comprehensive social survey of Bristol which is nearing completion has been made possible by the Colston Research Society, which has assumed entire financial responsibility, while the University undertook responsibility for the conduct of the research work and the appointment of the Survey staff. The preliminary report is only concerned with incomes which fall below middle-class levels, and covers four fifths of all Bristol families. The report indicates that, on the whole, the typical Bristol family is fortunately placed and probably better off than the families of many other towns. There are estimated to be 12,000 families in the Survey area which aro very comfortable by the prevailing standards, which are not high, in the classes covered. At the other end of the scale there are 11,000 families in poverty. Between these extremes thero are 56,000 families whose standard of living calls for no special remark, and some of these have a small margin for saving or pleasure. Beneath them come 21,000 families who, whilst not in poverty, have a hard struggle and whose lot is far from comfortable. Probably 40,000 people in the area live in actual poverty, and among them a disproportionate number of children, so that one out of five working-class children comes from a home that is unable to give it a fair start in life.

THE inquiry upon which the report is based was conducted from May to October 1937, coinciding roughly with the peak of the revival of business which started in 1932. The standard of minimum needs adopted in the survey in assessing poverty closely follows that used by Mr. R. F. George ( $J$. Roy. Statistical Soc., 100, 74 (1); 1937). The average Bristol working-class family has a standard of living more than 100 per cent above its minimum needs, and the average size of the family is only slightly above that of the middle class $(3.73$ in the poorest groups as against $2 \cdot 94$ in the most comfortable group). The rate of poverty is highest for those under fifteen and lowest for those in their twenties, being only 4.1 per cent in the age group 20-24. Unemployment is outstandingly the most important reason for family income falling below 'needs', and affects nearly one third of the families. Old age ranks third in importance, rather less than one sixth of the cases being assigned to it. Broken families, in which there is no adult male earner, account for 10 per cent of 
the cases and sickness for 9 per cent. Insufficient wages account for $\mathbf{2 1} \cdot \mathbf{3}$ per cent of all families below the standard.

\section{British Chemical Plant}

The reference in the leading article in Nature of January 28 to the report of the Association of Scientific Workers, and more particularly to the urgent need for more State assistance for fundamental research, receives further emphasis from a recent discussion by the British Chemical Plant Manufacturers Association, following an earlier meeting in May 1938. In the report above-mentioned it was specifically indicated that among the more urgent and important cases where State support is required is that of chemical engineering, notably in connexion with raw materials and unit operations. Although the discussions of the B.C.P.M.A. were at first intended to be limited to the question of closer collaboration between chemical manufacturers, chemical plant manufacturers and consultants, with the view of quoting for and providing complete process units, it soon became evident that the scope of debate would have to be extended to include co-operation on much wider grounds, including not only fundamental scientific research but also the economic question of meeting foreign competition effectively. It was not easy to come to any definite decision or formulate a constructive policy of basic research : this is a matter for further discussion between the main sections of the chemical industry and the Government. When one considers, however, the strenuous and for the most part successful efforts of recent years to place chemical engineering in Great Britain on a sounder basis, it is to be hoped that the matter will not be left where it is, in view of its supreme importance in regard to national well-being, export trade and defence.

ON the question of more effectively meeting foreign competition, some plant manufacturers find that there appears to be a tendency both on the part of certain Government departments and of some of the chemical manufacturers to assume too readily and complacently that the British makers of chemical plant and apparatus are sometimes unable or unwilling to tender for complete process units, especially in connexion with new processes ; and that this assumption has apparently formed the ground, or one of the grounds, for applications for licence to import foreign plant. The real truth, as was clearly shown at the last informal discussion of the British Chemical Plant Manufacturers Association, is that the need for these complete tenders from one firm is more infrequent than commonly supposed, and that, when it really does arise, the British manufacturer of plant is quite as well able as his foreign competitor to supply complete tenders if the inquiries are genuine and are accompanied by full details and complete designs. The allegation therefore that, whilst German or American firms will supply complete specifications and prices for the whole plant, it is necessary to apply to several different British firms for the various parts, with consequent greater delay, inconvenience, and enhanced cost, is not quite fair. Nevertheless the fact remains that much foreign plant has been and is still being imported. In addition to this discouragement, the British maker has to face ruthless Government-subsidized competition in foreign markets, and should therefore receive the greater support from his colleagues in the chemical industry and from the Government at home.

\section{Some Earthquakes Registered in 1937}

WE have received from Dr. W. Hiller the duca concerning earthquakes registered at Stuttgart, Ravensberg and Messtetten-Ebingen in 1937. Stuttgart is now equipped with three Galitzin-Wilip seismographs orientated north-south, east-west, and vertical, one Wiechert vertical seismograph of mass $1,320 \mathrm{kgm}$., two Mainka seismographs of mass 450 kgm. set north-south and east-west, a seismograph of mass $80 \mathrm{kgm}$. orientated east-west and a horizontal Wiechert instrument of mass $17,000 \mathrm{kgm}$. Ravensberg has two Mainka pendulums of mass $450 \mathrm{kgm}$. orientated north-south and east-west, and two Conrad seismographs of $23 \mathrm{kgm}$. also set north-south and east-west. Messtetten-Ebingen is equipped with one vertical Wiechert instrument of mass $80 \mathrm{kgm}$., and two horizontal pendulums of mass $80 \mathrm{kgm}$. orientated north-south and east-west. The full list of constants for all these insiruments is given. The main part of the report concerns the 426 earthquakes registered at these stations during 1937. For each shock recorded a full list of readings, including date, registering station, component, phase, arrival time, period, amplitude in $\mu$, and remarks chiefly concerning the epicentre and epicentral distance from the station, is given. Lastly, there follow two valuable additions to the compilation. First comes a tabulation of microseisms registered on the GalitzinWilip seismometers at Stuttgart, including the period and amplitude in $u$ on the three components, and secondly a careful study of the Hohenzollernalb earthquake of June 17, 1937. The epicentre of this is found to be $48^{\circ} 15 \cdot 3^{\prime}$ N., $9^{\circ} 12 \cdot 4^{\prime}$ E., 上2-3 km., depth of focus $19-20 \mathrm{~km}$. \pm about $4 \mathrm{~km}$, and $T^{\prime}$ $9 \mathrm{~h} .56 \mathrm{~m} .41 \cdot 8 \mathrm{~s} . \pm 0 \cdot 3 \mathrm{~s}$. The publication forms a very valuable addition to the data and literature of seismology.

\section{'Commercial' Water Culture of Plants}

AN amusing example of the way in which the publicity of the Press may embarrass scientific workers is provided by the need for Circular 347 of the Agricultural Experiment Station, Berkeley, California, in which D. R. Hoagland and D. I. Arnon have to try to dispel illusions about the commercial possibilities of growing plants by water culture. The authors point out that the technique of water culture contains nothing new and has indeed been employed for more than a quarter of a century by this experiment station, whilst the method was, of course, described by the German physiologist Sachs in his text-book about 1860. The California Experiment Station must rue the day that Dr. W. F. Gericke conceived the idea that the method might have some 